University of Nebraska - Lincoln

DigitalCommons@University of Nebraska - Lincoln

\title{
$7-2018$
}

\section{Improving the calibration of silicon photodiode pyranometers}

\author{
Elizabeth Walter-Shea \\ University of Nebraska-Lincoln, ewalter-shea1@unl.edu \\ Kenneth Hubbard \\ University of Nebraska - Lincoln, khubbard1@unl.edu \\ Mark A. Mesarch \\ University of Nebraska - Lincoln, mmesarch1@unl.edu \\ Glen Roebke \\ University of Nebraska-Lincoln, groebke1@unl.edu
}

Follow this and additional works at: https://digitalcommons.unl.edu/natrespapers

Part of the Natural Resources and Conservation Commons, Natural Resources Management and Policy Commons, and the Other Environmental Sciences Commons

Walter-Shea, Elizabeth; Hubbard, Kenneth; Mesarch, Mark A.; and Roebke, Glen, "Improving the calibration of silicon photodiode pyranometers" (2018). Papers in Natural Resources. 732.

https://digitalcommons.unl.edu/natrespapers/732

This Article is brought to you for free and open access by the Natural Resources, School of at DigitalCommons@University of Nebraska - Lincoln. It has been accepted for inclusion in Papers in Natural Resources by an authorized administrator of DigitalCommons@University of Nebraska - Lincoln. 


\title{
Improving the calibration of silicon photodiode pyranometers
}

\author{
Elizabeth A. Walter-Shea, ${ }^{1}$ Kenneth G. Hubbard, ${ }^{2}$ \\ Mark A. Mesarch, ${ }^{1}$ and Glen Roebke ${ }^{3}$
}

1 School of Natural Resources, University of Nebraska-Lincoln, 3310 Holdrege Street, Hardin Hall, Lincoln, NE 68583-0968

2 P.O. Box 92, Cortland, NE 68331-0092

3 Nebraska State Climate Office and School of Natural Resources, University of Nebraska-Lincoln, 3310 Holdrege Street, Lincoln, NE 68583

Corresponding author — Elizabeth A. Walter-Shea, email ewalter-shea1@unl.edu

\begin{abstract}
Reliable measurements of global irradiance are essential for research and practical applications. Silicon photodiode pyranometers (SiPs) offer low-cost sensors to measure direct and diffuse irradiance despite their non-uniform spectral response over the 300-1000 nm spectral range. In this study, non-adjusted linear and adjusted calibrations were applied at different times of the year to determine sources of estimated errors in global irradiance due to the two calibration approaches, calibration time, and sensor age. $16 \mathrm{SiPs}$, along with two standards, measured incident global irradiance over a 5 -year period under a range of sky conditions. Sensors performed best in the months in which they were calibrated when using the linear calibration approach. With the solar zenith angle adjusted calibration approach, certain calibration months provide a defendable validation for the following 12 months [ranging an average of 13.5-17.4 $\mathrm{W} \mathrm{m}^{-2}$ standard error (SE)], while other calibration months do not provide consistent results and sometimes result in very poor validation (31.1-242.7 $\mathrm{W} \mathrm{m}^{-2} \mathrm{SE}$ ). Older sensors (greater than 6 years) in general become more sensitive to solar zenith angle and their response drifts over time, while newer SiPs performed better than older sensors. Calibrations which accounted for solar zenith angle effects improved global irradiance estimates for older SiPs. For the Lincoln NE location, the appropriate calibration is in spring or late summer, regardless of calibration approach. These results indicate that solar zenith angle correction is not needed for largely diffuse components under cloudy conditions, so that in the future, a "smart" calibration may be possible, where diffuse radiation fractions are known.
\end{abstract}




\section{Introduction}

Reliable measurements of global irradiance are essential for a number of research and practical applications. Silicon photodiode pyranometers (SiPs) offer a low cost alternative to thermopile-based pyranometers and are used worldwide to measure global irradiance. In addition to their low-cost advantage, these sensors are small, lightweight, and can be easily used to measure diffuse irradiance when incorporated with a shadow band. Knowing total and diffuse irradiance, direct irradiance can be determined.

SiPs have a spectral response covering the $300-1100 \mathrm{~nm}$ spectral range, which is about $75 \%$ of the total energy in the $300-4000 \mathrm{~nm}$ terrestrial solar spectral range (Myers 2011). In contrast, thermopile pyranometers (such as the Eppley precision spectral pyranometer) measure global irradiance in the 285-2800 $\mathrm{nm}$ range, which includes most of terrestrial solar energy. The spectral response of SiPs is also non-uniform. Thus, SiPs should not be used to measure the radiation reflected from the earth's surface, because global irradiance for sky conditions is accommodated in the calibration. Solar zenith and azimuth angles and various atmospheric conditions influence the quality and quantity of global irradiance. Myers (2011) found the SiPs lack sensitivity to spectral differences of varying atmospheric conditions, which can lead to errors of about $2 \%$ in global irradiance measurements and greater in diffuse irradiances. Al-Rasheedi et al. (2018) found SiP responses deviated from those of thermopile sensors within $\pm 5 \%$ and raised concerns about diffuse irradiance measurements due to an insufficient spectral correction. Diffuse radiation contains a higher proportion of blue light due to Rayleigh scattering. Thus, diffuse irradiance differs spectrally from direct irradiance from the sun, such that SiPs measuring diffuse irradiance respond differently under a cloudless sky than under skies covered with clouds (Vignola et al. 2016). Various corrections have been applied to SiPs to compensate for the effects of temperature, spectral sensitivity, and cosine error, especially when used in rotating shadow band applications (Geuder et al. 2014; Vignola et al. 2016; Al-Rasheedi et al. 2018). Thus, it is ideal to calibrate SiPs on site during periods of atmospheric conditions representative of conditions that occur during the entire year.

Group calibration approaches, in which a number of SiPs are deployed with a secondary standard (e.g., an Epply precision spectral pyranometer, PSP), have been used in large field projects such as automated networks to measure solar global irradiance (e.g., Aceves-Navarro et al. 1988). The calibration data, collected side-by-side under field conditions, are analyzed using regression. The output from the SiPs is typically the dependent variable and output from a secondary standard is the independent variable, with slope and intercept providing the specific calibration constants for use in 
the field. Previously, calibration included two clear sky days occurring within a 10-day window. "The principal advantage of outdoor calibration of radiometers is that all pyranometers are related to a single reference under realistic irradiance conditions" (ASTM 2010). The Nebraska Mesonet, operated by the Nebraska State Climate Office (NSCO), calibrates SiP sensors annually (LI-COR LI-200s at the time of this paper). The calibration procedure used by the NSCO is fully described in Aceves-Navarro et al. (1988). We refer to this calibration approach as the non-adjusted linear calibration, because no environmental factors (such as angle of incidence or sensor temperature; see below) are taken into account.

King and Myers (1997) reported "silicon photodiode pyranometers can vary with their calibration by month and that over a 1-year period, month to month (seasonal) variations of about $5 \%$ were observed in the apparent calibration factor." They cite factors that require corrections to the apparent calibration including sensor temperature, the absolute air mass $\left(A M_{a}\right)$, and angle of incidence (AOI). King et al. (1998) demonstrated that by applying corrections, SiPs can provide accuracies of $\pm 3 \%$, whereas instantaneous measurements without corrections can differ by as much as $15 \%$. Solar spectra at sunrise or sunset have a higher percentage of longer wavelength irradiance than spectra at midday. Thus, pyranometers can be expected to respond to changes in solar spectra, changes for which SiP measurements may not reliably respond due to calibration limitations. A calibration that takes into account additional factors, as provided by King and Myers (1997), is referred to here as an adjusted calibration.

LI-COR Inc. (Lincoln, NE USA) recommends a calibration of their silicon photodiode pyranometers (Li-200s) be performed every 2 years after sensor field deployment. They recommend calibration between the months of March and September for the Lincoln, NE location when these sensors are exposed to a full range of sun light intensities over a broad range of sun angles.

The objective of this study is to determine errors in two calibration approaches [non-adjusted linear calibration (described in Aceves-Navarro et al. 1988) and adjusted calibration] in estimating solar global irradiance using SiPs under outdoor conditions over the course of a year. A program module to select clear sky days for calibration was developed as an outcome in addressing this objective. 


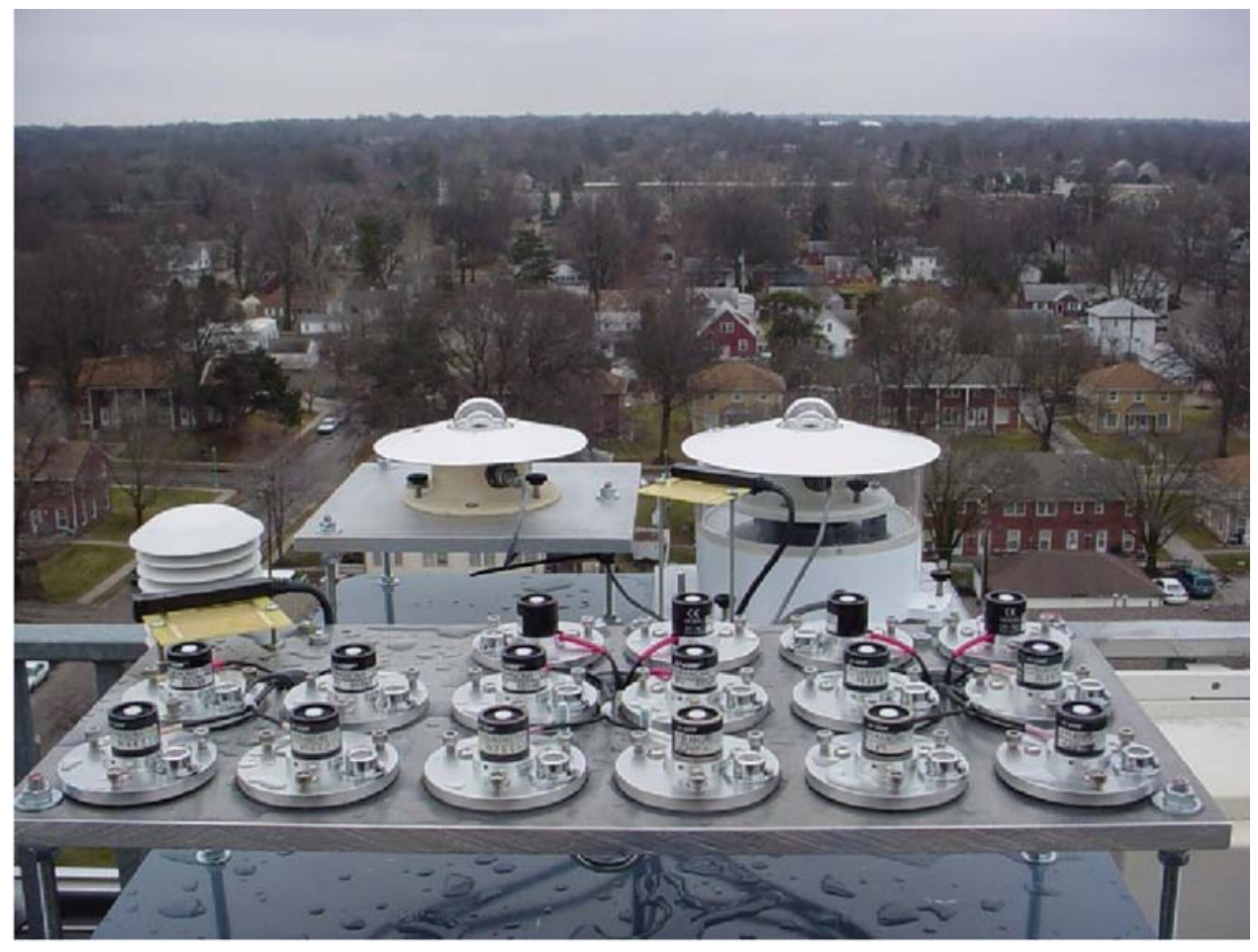

Fig. 1. Pyranometers mounted on the aluminum plate surface of a leveling table on the roof of a nine-story building (Hardin Hall, University of Nebraska-Lincoln). The silicon photodiode pyranometers are in the foreground and the Eppley precision spectral pyranometers (PSPs) are in the background. An air temperature thermistor and its shield are in the back left.

\section{Experimental design}

A total of 16 silicon photodiode pyranometers (SiPs; LICOR model LI-200²) were mounted on an aluminum plate along with two secondary standards [precision spectral pyranometer (PSP), Newport, RI, USA], and a temperature and relative humidity probe (HMP45C-L Campbell Scientific, Inc., Logan, UT, USA) for measuring air temperature at the time of measurement (Fig. 1). All photoreceptors were at a common elevation. The equipment was set on the roof of an isolated nine-story building on the University of Nebraska- Lincoln East Campus to avoid ground reflectance and shadowing from surrounding buildings or trees. The PSPs used in this study as secondary standards were calibrated by the manufacturer [traceable to the world radiometric reference (WRR)] before the experiment and every 2 years during the 5 -year

1. Mention of manufacturer's name does not imply endorsement of a product over those offered by other manufacturers but is provided for the convenience of the reader. 
Table 1. Calibration dates and coefficients for each standard (Eppley PSP) over the life of the study.

\begin{tabular}{|c|c|c|c|c|}
\hline \multirow[t]{2}{*}{ Calibration } & \multicolumn{2}{|c|}{ PSP1 (\#26227F3) } & \multicolumn{2}{|c|}{ PSP2 (\#36159F3) } \\
\hline & Date & $\begin{array}{l}\text { Coefficient } \\
\left(\mu \vee N m^{-2}\right)\end{array}$ & Date & $\begin{array}{l}\text { Coefficient } \\
\left(\mu \vee / W m^{-2}\right)\end{array}$ \\
\hline 1 & $22 \operatorname{Jan} 2010$ & 8.66 & 6 Jan 2010 & 8.66 \\
\hline 2 & 3 Jan 2012 & 8.32 & 1 Feb 2012 & 8.23 \\
\hline 3 & 17 Jan 1014 & 8.24 & 14 Feb 2014 & 8.07 \\
\hline
\end{tabular}

study period (Table 1). Analog voltage readings from each sensor were measured every $5 \mathrm{~s}$, averaged over a 10-min period, and stored on a data logger (model CR3000, Campbell Scientific, Logan, UT, USA).

Measurements began on 13 March 2010 and ended on 16 March 2015 (a 5 -year period), with sensors regularly maintained and cleaned according to manufacturer recommendations. Data from the sensors were quality checked (manually) for errors introduced by snow or other debris on the sensors, missing data, and divergence between the two PSP responses (within $\mathrm{d}$-statistic of 0.95); erroneous data were removed from the analyses. For example, differences in response between and among PSPs and SiPs on days following snow events recorded at the local municipal airport prompted removal of the data from analysis.

Eight of the $16 \mathrm{LI}-\mathrm{COR} \mathrm{LI}-200 \mathrm{SiPs}$ were purchased in 2010 (referred to here as "new" sensors and numbered 9-16 for this study); the remaining eight SiPs ranged in age from 7 to 15 years at the initiation of the study (referred to as "old" sensors and numbered 1-8 for this study).

\section{Methods}

Key to calibrations was the identification of clear sky days using an appropriate number of 10-min observations (regardless of time of year). The selection criterion for clear sky calibration data for this study was based on calibration trials investigating the choice of solar zenith angle maximum $\left(60^{\circ}, 70^{\circ}\right.$, and $\left.80^{\circ}\right)$ (unpublished). Based on these trials, a maximum solar zenith angle of $80^{\circ}$ was selected. This criterion provided the greatest number of observation days ( $5 \mathrm{~h}$ or more during the day), especially in the winter months, at the study latitude. Data with solar zenith angles larger than $80^{\circ}$ were not used in the calibrations.

The procedure for selecting clear sky days consisted of two parts. A MATLAB-based program was used to determine the residual ( $36 \mathrm{~W} \mathrm{~m}^{-2}$ or less) between a fitted Fourier curve (a two-term Fourier model as input argument 
(a)
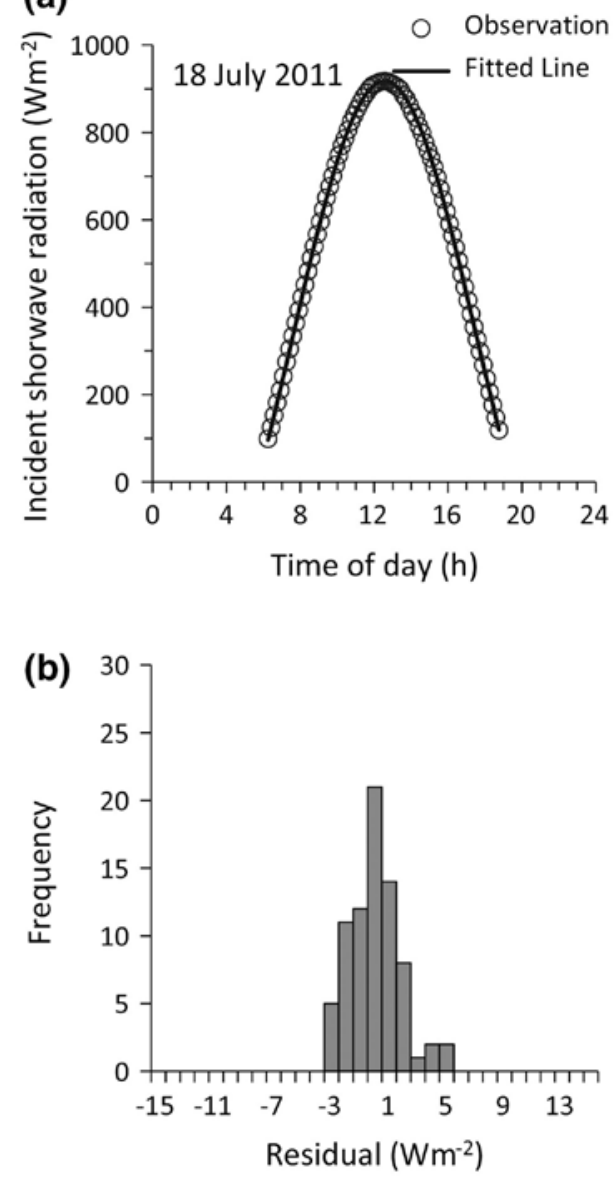

(c)
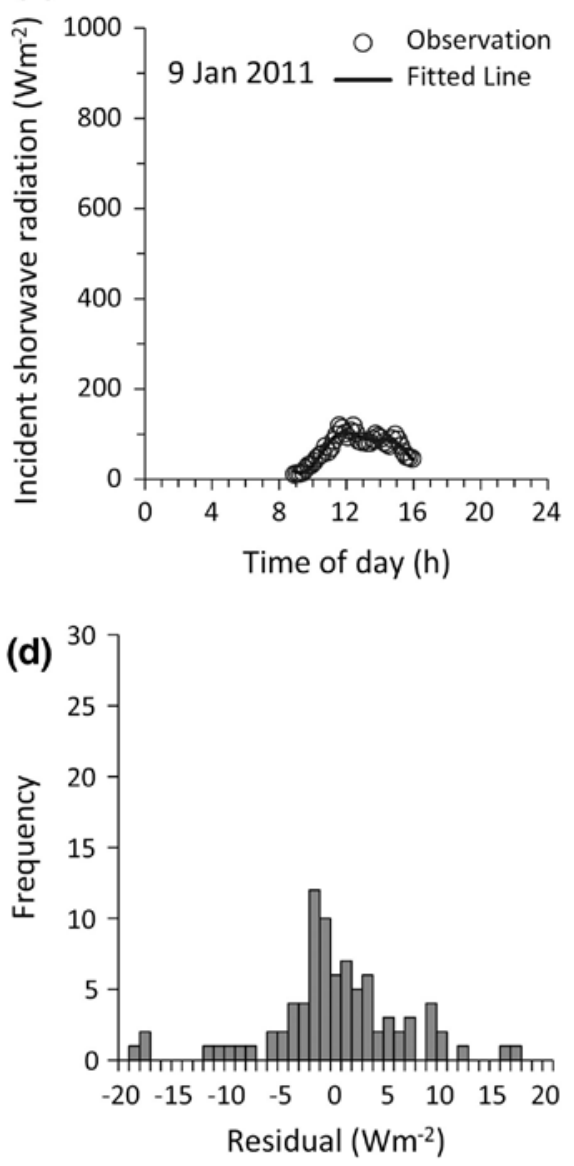

Fig. 2. Two-term Fourier model fit of observed pyranometer data for a) 18 July 2011 and c) 9 Jan 2011 and residuals (PSP observation - curve value), b), d), respectively. 18 July 2011 was correctly identified as a clear sky day, while 9 Jan 2011 (although it had a low residual) was eliminated after visual inspection.

to the MATLAB polyfit function) and an observed PSP global irradiance as a means of initially identifying days with clear sky conditions. Daily data meeting the solar zenith angle and residual criteria were graphed. Daily clear sky graphs yielded a smooth single peaked curve and low residuals (e.g., 18 July 2011 in Fig. 2a, b, respectively). The Fourier-fitted curve graphs and observed global irradiance were visually compared; those days not representing a typical clear sky curve were not considered for calibration (e.g., 9 Jan 2011 in Fig. 2c, d, respectively); manual oversight was necessary to refine the search, because low residuals can result in false-positive selection (e.g., no single peaked curve), as illustrated in Fig. 2c, d. Note that the program can be used for any location specified in the user input, provided that the pyranometer data are in the appropriate format. 


\subsection{Non-adjusted linear calibration}

From the set of identified clear sky days, a pair of clear sky days was selected within a 10-day moving window with a minimum of $10 \mathrm{~h}$ total for the 2 days (i.e., a minimum of 60, 10-min averaged observations). Tests indicated that $10 \mathrm{~h}$ or more of observations meeting the solar zenith angle requirement were necessary during the 2-day calibration period for reliable SiP calibrations.

The clear sky day pairs were used in a non-adjusted linear calibration following the approach of Aceves-Navarro et al. (1988):

$$
E_{t n}=a+b \frac{E_{\mathrm{o}}}{C_{n}} R
$$

where $E_{t n}$ is the estimate of global irradiance $\left(E \mathrm{~W} \mathrm{~m}^{-2}\right), R$ is the sensor signal $(\mathrm{mV})$ from the SiP being calibrated, and $E_{0} / C_{n}$ is a scaling factor [200 W m-2 $\mathrm{mV}^{-1}$, dependent on a reference global irradiance and sensor response]; $a$ is the intercept, $b$ is the slope found through linear regression (Aceves-Navarro et al. 1988). The Aceves-Navarro et al. non-adjusted linear calibration approach does not take into account environmental factors such as angle of incidence or sensor temperature.

Linear regression was used to estimate the coefficients $a$ and $b$ for the selected clear sky days. The product of the scaling factor and sensor response $\left(E_{0} / C_{n} \times R\right)$ was regressed against average PSP global irradiance values to calculate coefficients $a$ and $b$. The calibration was then applied to the remaining SiP output data from the 12-month period following the month of calibration, regardless of sky condition (e.g., calibration in May 2011 was validated using data from June 2011 through May 2012). A regression of estimated 10 -min average irradiances to the average of the two PSP standard 10-min average global irradiance was used to determine the error resulting from the use of that particular calibration pair and sensor; all sensors were calibrated individually. The standard error (SE) was used as a measure of the amount of error in the estimation of global irradiance $\left(E_{t n}\right)$ for individual average global irradiance of the two PSP standards $(E)$ values. Standard errors for the validations were averaged for each monthly period over the 5-year period for all sensors to identify the trend in calibration performance [i.e., average of all SE in comparing estimated global irradiance to PSP-measured global irradiance (Eq. 1) for all calibration pairs in each month over the 5-year period]. Results were summarized into an average SE for each month over all 5 years (along with the standard deviation about the average SE). 
Calibrations were also derived using all clear sky data in a year and then validated for all days (regardless of sky condition) in a 12-month period following the month of calibration. For each calibration, SE was calculated for the year. Results were summarized into an average SE over all 5 years (and a standard deviation about the average SE).

\subsection{Adjusted calibration}

King and Myers (1997) suggested a calibration that accounts for solar zenith angle, temperature, and atmospheric conditions:

$$
E_{t}=\frac{R\left(E_{\mathrm{o}} / C_{n}\right)\left[1-\alpha\left(T-T_{0}\right] f(Z)\right.}{g\left(\mathrm{AM}_{\mathrm{a}}\right)}
$$

where $E_{t}$ is the estimate of the PSP observed global irradiance based on the adjustment to the SiP for temperature $(T)$, absolute air mass, $g\left(\mathrm{AM}_{\mathrm{a}}\right)$, and the solar zenith angle, $f(Z)$. $R$ is the response from the $\operatorname{SiP}(\mathrm{mV}), T$ is the temperature of the sensor $\left({ }^{\circ} \mathrm{C}\right), T_{0}$ is the reference temperature $\left(25^{\circ} \mathrm{C}\right), \alpha$ is a temperature coefficient, and $E_{0} / C_{n}$ is as described earlier. Sensor temperature was assumed equal to air temperature. King and Myers (1997) found the function $g\left(A_{a}\right)$ to vary from 0.98 to 1.02 as $A M_{a}$ varied from 1 to 2 . As $\mathrm{AM}_{\mathrm{a}}$ data are not readily available, a value of 1.0 is assumed for $g\left(\mathrm{AM}_{\mathrm{a}}\right)$ in this study.

Stepwise regression was used to estimate the polynomial, $f(Z)$, and to correct for sensor temperature $(T)$. The ratio, $E_{t} / y_{n}$ (where $y_{n}=R \times E_{d} / C_{n}$ ), was plotted against $Z$ to estimate the function $f(Z)$. The second step in the regression was to plot the value of $\left.E_{t} /[f(Z))\left(y_{n}\right)\right]$ against $(T-25)$ to derive the values of $\alpha$ and $\beta$, coefficients of the regression, where $\beta$ is a value close to 1 and, therefore, serves as an approximation of the value of 1 in Eq. 2. Thus, the "adjusted calibration approach" used in this study is represented by

$$
E_{t}=R\left(E_{\circ} / C_{n}\right)[\beta-\alpha(T-25)] f(Z)
$$

To account for all possible solar zenith angle and air temperature conditions for a year, calibrations were derived using all clear sky data in a year and validated for all days in the remaining years. Investing in a calibration based on clear sky data collected over a year's time may be unrealistic for users, so the calibration was also limited to a month-long period as a means of determining suitable times of year for calibration. As with the non-adjusted calibration, the adjusted calibration approach was validated for all days in a 12-month period following the month of calibration (e.g., calibration in May 2011 was validated using data from June 2011 through May 
2012). In addition, an SE was calculated for the year and for each validation month as a means of determining suitable times of year for calibration. The results were summarized into an average SE for each month over all 5 years (standard deviation about the average SE was also computed).

Validations yielding lower monthly averaged SE over the course of the year and overall 5 years were deemed better months for calibration for the Lincoln location and provided a means to evaluate the calibration approaches.

\section{Results}

A typical non-adjusted linear calibration result using a pair of clear sky days within a 10-day window is shown in Fig. 3 for a representative "new" and "old" sensor. A high $R^{2}$ (e.g., $R^{2}=0.99$ ) was typical for all 16 sensors calibrated as part of this study; the SE varied among the sensors from 4.9 to $12.5 \mathrm{~W} \mathrm{~m}^{-2}$, and suggests a precise relationship between the SiP and the PSP. Validation of this performance, using independent datasets, is described later.

Sensor responses from the PSP and SiPs for selected clear sky days (e.g., Fig. 3) were used to derive linear calibration coefficients for each SiP for the respective month. The calibrations were subsequently validated using an independent PSP data set collected at the same time as the SIPs over the remaining months and days (including non-clear times). Typical validation SE results for the non-adjusted linear calibration are illustrated for calibration
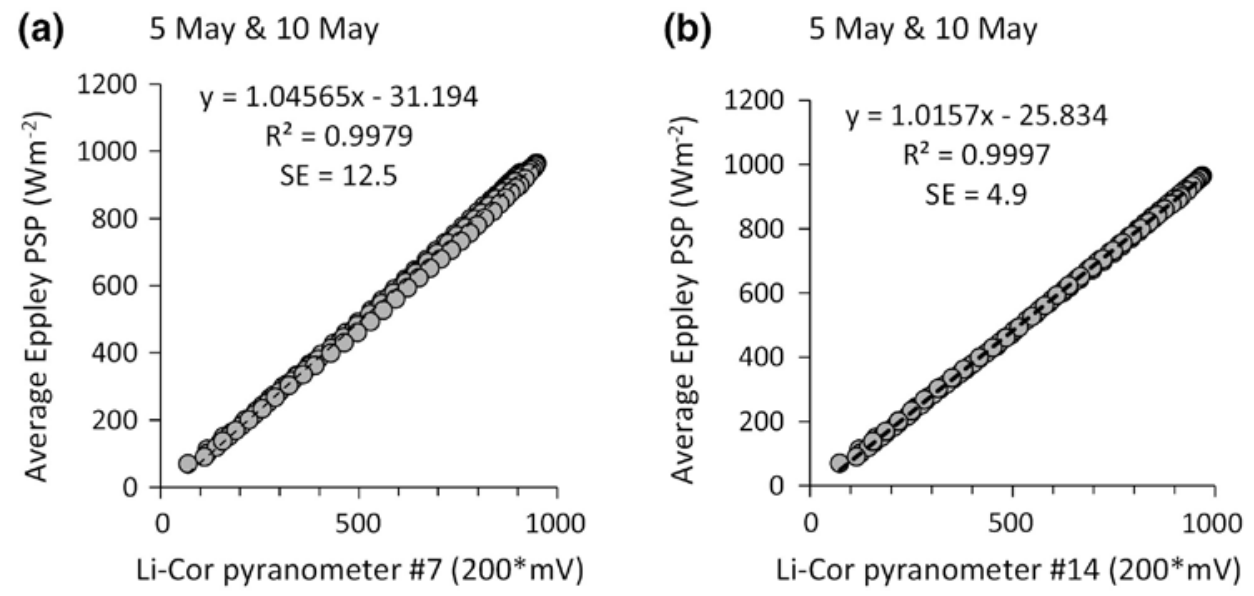

Fig. 3. Example of non-adjusted linear calibration [see Eq. (1)] for pyranometer a) \#7 (old) and b) \#14 (new) for 2 days in a 10-day window in 2012. 

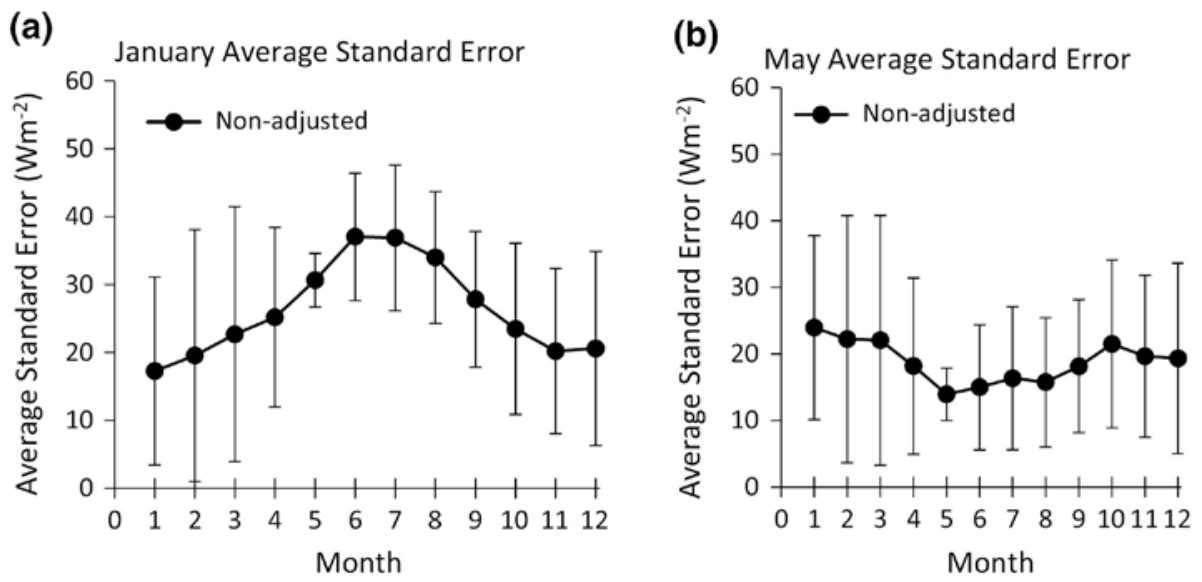

Fig. 4. Monthly average validation results for non-adjusted linear calibration for all sensors, across the 5-year study period, from a) January and b) May over the 5 -year study.

months January and May (Fig. 4). The monthly average SE ranged from about $17-37 \mathrm{~W} \mathrm{~m}^{-2}$ for the January calibrations with individual sensors as high as $99 \mathrm{~W} \mathrm{~m}^{-2}$. Monthly performance for the May non-adjusted linear calibrations ranged from about 14-24 $\mathrm{W} \mathrm{m}^{-2}$, with an SE of $69 \mathrm{~W} \mathrm{~m}^{-2}$ for some sensors. As expected, the SEs for the validation are much higher than the SE for the calibration example (Fig. 3) due to greater variability in sky conditions over the validation period. Sensors performed best in the months in which they were calibrated (as indicated by average monthly SE), although variability was greater for calibrations conducted in the winter months.

Because of seasonal influences on estimated global irradiance values and errors associated with the non-adjusted linear calibration, as represented by the SE values (Fig. 4), we expect the adjusted calibration approach [Eq. (3)], which accounts for the effect of air temperature $(T)$ and solar zenith angle $(Z)$ on sensor response using stepwise regression, would improve the results. Sensor response to $Z$ required a second-order polynomial, while a linear equation worked well for the $T$ effect. An example of the stepwise regression calibration result for SiP \#14 (i.e., a "new" sensor) for four clear sky days in May 2012 is provided in Fig. 5 (Fig. 5a illustrates the second-order polynomial describing the sensor response to $Z$ and Fig. $5 b$ illustrates the linear equation describing the sensor response to $T$ ). Reversing the order of the stepwise regression gave a similar result for this "new" sensor (Fig. 6).

Note the $T$ effect is more pronounced when temperature is addressed in the first step of the stepwise regression compared to when it is the second step, where the slope is near zero and the intercept is one. This indicates a sensor response in which $Z$ and $T$ effects are not totally independent. Accounting for solar zenith angle in the first step reduces the impact of $T$ on 

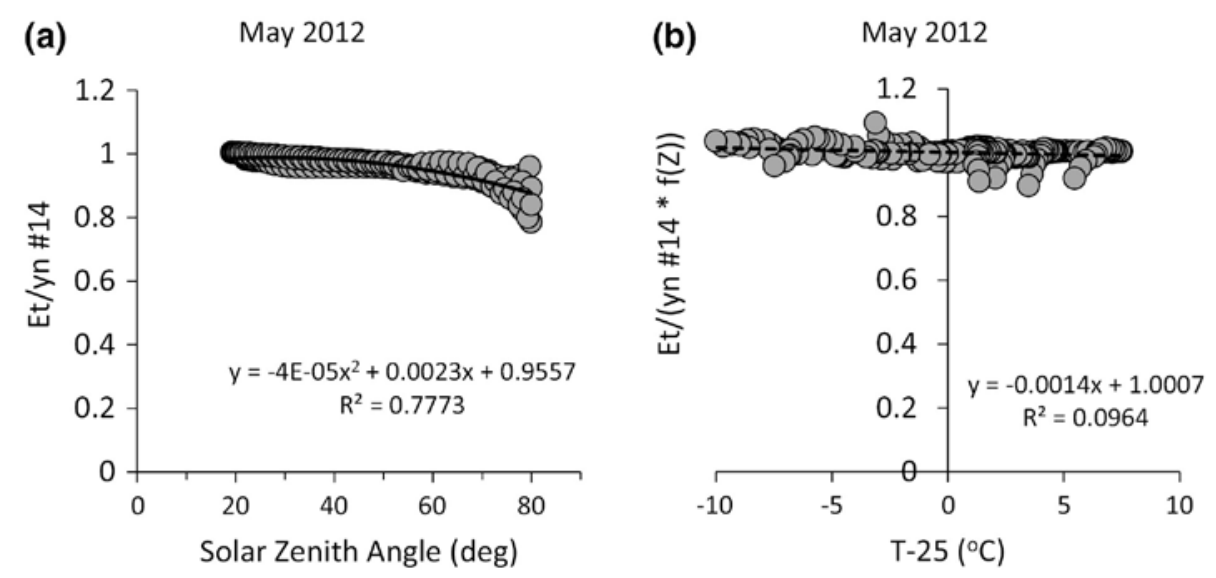

Fig. 5. Stepwise regression calibration for LI-COR LI-200 pyranometer \#14 for clear sky days (5 May, 10 May, 15 May and 28 May) in 2012: a) polynomial relation for solar zenith angle correction and $\mathbf{b})$ linear air temperature correction.
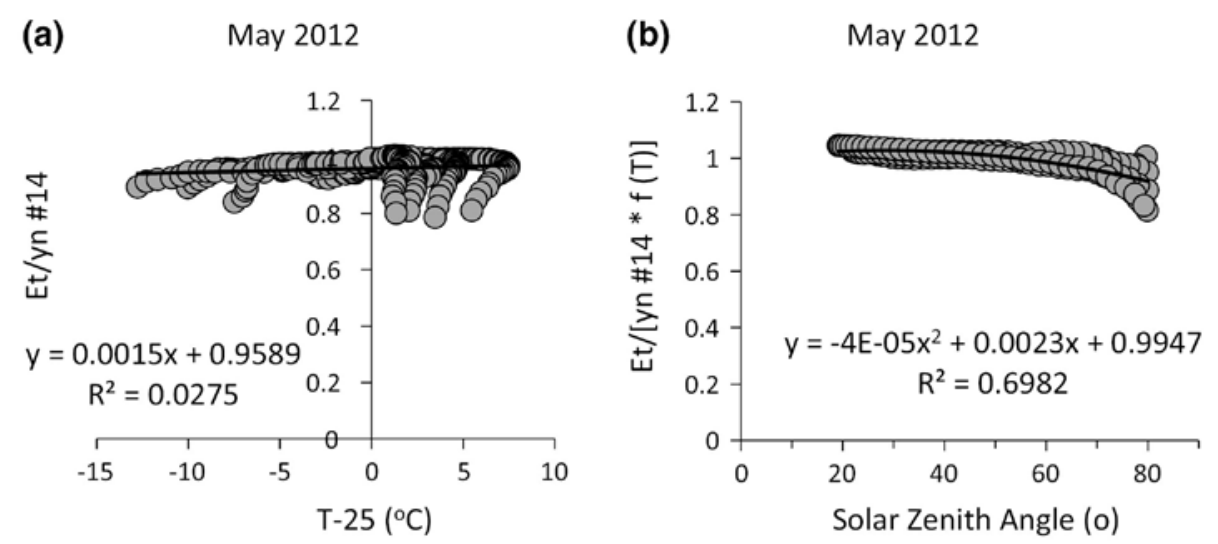

Fig. 6. Stepwise regression calibration for LI-COR LI-200 pyranometer \#14 for clear sky days (5 May, 10 May, 15 May, and 28 May) in 2012: a) temperature correction; and b) polynomial relation for solar zenith angle correction.

sensor response to global irradiance. The ratios which depart from the general trend in the data (Figs. 5b, 6a), referred to here as ratio "tails," are attributed to the time lag in response of the sensor to $T$.

To account for all possible solar zenith angle and air temperature conditions for a year, calibrations were derived using all clear sky data in a year, i.e., an annual calibration. The approach was applied to all clear sky conditions for each of the remaining years of the study (annual calibration).

Overall, the yearly adjusted (stepwise regression) calibration performed better (lower SE) than the yearly nonadjusted linear approach (Table 2). In the non-adjusted linear calibration approach, the "old" sensors (1-8) had an 
Table 2. Calibration results for each of the 16 pyranometers in the study for the three calibration approaches (the average of five annual standard errors and the resulting standard deviation of the standard error shown in parentheses).

\begin{tabular}{|c|c|c|c|c|c|}
\hline \multirow[t]{2}{*}{ Pyranometer \# } & \multirow{2}{*}{$\begin{array}{c}\text { Non-adjusted } \\
\left(W m^{-2}\right)\end{array}$} & \multicolumn{2}{|c|}{$\begin{array}{l}Z \text { and } T-25^{\circ} \mathrm{C} \text { adjusted } \\
\text { (stepwise regression) }\end{array}$} & \multicolumn{2}{|c|}{$\begin{array}{l}T-25^{\circ} \mathrm{C} \text { and } Z \text { adjusted } \\
\text { (stepwise regression) }\end{array}$} \\
\hline & & $\begin{array}{l}\text { Z only } \\
\left(W m^{-2}\right)\end{array}$ & $\begin{array}{c}Z \text { and } T-25^{\circ} \mathrm{C} \\
\left(W m^{-2}\right)\end{array}$ & $\begin{array}{l}\text { Tonly } \\
\left(W m^{-2}\right)\end{array}$ & $\begin{array}{r}T-25{ }^{\circ} \mathrm{C} \text { and } Z \\
\left(W m^{-2}\right)\end{array}$ \\
\hline 1 & $19.1(5.7)$ & $15.1(6.0)$ & $12.6(5.9)$ & $14.1(7.0)$ & $14.3(6.1)$ \\
\hline 2 & $23.2(7.3)$ & $17.9(6.8)$ & $15.2(7.0)$ & $17.7(8.1)$ & $17.8(6.4)$ \\
\hline 3 & $14.4(2.2)$ & $10.6(1.2)$ & $10.6(1.2)$ & $13.7(2.2)$ & $13.3(2.0)$ \\
\hline 4 & $25.6(4.1)$ & $17.4(5.0)$ & $12.3(4.1)$ & $15.5(4.6)$ & $15.0(4.1)$ \\
\hline 5 & $11.3(0.3)$ & $9.0(0.6)$ & $8.5(0.7)$ & $11.0(1.4)$ & $11.4(1.5)$ \\
\hline 6 & $12.6(1.9)$ & $9.0(1.4)$ & $8.8(1.6)$ & $11.8(2.3)$ & $11.7(2.3)$ \\
\hline 7 & $27.5(9.9)$ & $19.9(7.1)$ & $16.2(4.8)$ & $20.0(6.2)$ & $18.0(4.6)$ \\
\hline 8 & $24.3(3.5)$ & $19.5(2.9)$ & $17.9(3.3)$ & $21.5(4.0)$ & $20.2(4.2)$ \\
\hline 9 & $14.1(2.6)$ & $12.1(3.0)$ & $12.0(3.0)$ & $13.4(3.0)$ & $12.8(2.4)$ \\
\hline 10 & $10.1(1.5)$ & $8.3(1.2)$ & $7.9(1.1)$ & $9.3(1.5)$ & $10.0(1.7)$ \\
\hline 11 & $12.6(3.8)$ & $12.5(4.1)$ & $11.9(3.5)$ & $11.9(3.2)$ & $11.1(2.9)$ \\
\hline 12 & $10.4(2.8)$ & $9.1(2.2)$ & $9.0(2.2)$ & $10.0(2.7)$ & $10.6(2.2)$ \\
\hline 13 & $7.8(1.0)$ & $7.6(0.9)$ & $7.4(0.9)$ & $7.9(1.0)$ & $8.8(1.3)$ \\
\hline 14 & $14.1(4.2)$ & $11.2(3.0)$ & $10.3(1.8)$ & $11.6(1.8)$ & $11.5(1.6)$ \\
\hline 15 & $9.2(1.2)$ & $7.8(1.0)$ & $7.5(1.0)$ & $8.5(1.4)$ & $9.3(1.6)$ \\
\hline 16 & $9.1(1.2)$ & $8(1.1)$ & $7.9(1.2)$ & $8.7(1.2)$ & $9.2(1.5)$ \\
\hline Overall & $15.3(2.5)$ & $12.2(2.2)$ & $11.0(1.9)$ & $12.9(2.2)$ & $12.8(1.7)$ \\
\hline Old sensors & $19.7(3.1)$ & $14.8(2.7)$ & $12.8(2.3)$ & $15.7(2.4)$ & $15.2(1.8)$ \\
\hline New sensors & $10.9(1.3)$ & $9.6(1.2)$ & $9.2(1.0)$ & $10.2(0.9)$ & $10.4(0.6)$ \\
\hline
\end{tabular}

Calibrations were conducted for an entire year of clear sky data: (1) non-adjusted linear, (2) adjusted using stepwise regression, where the solar zenith angle $(Z)$ adjustment is derived first, and (3) adjusted using stepwise regression, where the temperature ( $T$ ) adjustment is derived first. Overall average results are provided for all 16 sensors as well as average results for the "old" and "new" sensors.

average SE (for the entire calibration period) of $19.7 \mathrm{~W} \mathrm{~m}^{-2}$ compared to an average $10.9 \mathrm{~W} \mathrm{~m}^{-2}$ for the "new" sensors (9-16). The calibration approach using the $Z$ adjustment first, followed by the $T$ adjustment, was slightly advantageous compared to the calibration approach using $T$ first followed by the $Z$ correction in the stepwise regression. For the "old" sensors, the $Z$ adjustment reduced the SE from 19.7 to 14.8, an improvement of nearly $5 \mathrm{~W}$ $\mathrm{m}^{-2}$. The "new" sensors $Z$ adjustment calibration SE reduced the SE from 10.9 to $9.6 \mathrm{~W} \mathrm{~m}^{-2}$, an improvement of only $1.3 \mathrm{~W} \mathrm{~m}^{-2}$. 
Note that the improvement achieved by calibration based on a year's worth of clear sky data may be unrealistic for sensor users. Limiting the calibration to a month-long period, for particular months, provides an adequate range in solar zenith angle (Fig. 5), but unfortunately does not adequately represent the annual temperature range to identify the temperature effect. Note differences between "old" and "new" sensors with little improvement by correcting for temperature in either stepwise regression approach (further demonstrated in Fig. 5b). Thus, the temperature effect was dropped from the analysis and a monthly calibration was adopted for the adjusted calibration approach (adjusting for $Z$ only).

As with the non-adjusted calibration approach, the adjusted calibration approach was validated for all days in a 12-month period following the month of calibration. Validation results for each monthly calibration indicate that certain calibration months have the lowest SEs and provide a defendable validation across the following year-long period (values in bold, Table 3), while other calibration months do not provide consistent results

Table 3. Overall standard error (the average of annual standard errors for all 16 pyranometers over the remaining 4 years of validation) and the resulting standard deviation of the standard error shown in parentheses) for validation results, where calibrations were conducted during the designated month for the non-adjusted linear calibration approach using pairs of clear sky days and the solar zenith angle adjusted calibration approach using clear sky days for the designated month.

Month of calibration

All pyranometers

\begin{tabular}{|c|c|c|}
\hline & \\
\hline & \multicolumn{2}{|c|}{ Validation average SE $\left(\mathrm{W} \mathrm{m}^{-2}\right)$} \\
\hline & $\begin{array}{r}\text { Non-adjusted } \\
\text { (pair of days) }\end{array}$ & $\begin{array}{c}\text { Adjusted } Z \text { regression } \\
\text { (monthly) }\end{array}$ \\
\hline January & $26.3(14.3)$ & $98.8(52.0)$ \\
\hline February & $20.1(9.7)$ & $242.7(501.7)$ \\
\hline March & $20.0(12.0)$ & $17.4(8.4)$ \\
\hline April & $19.8(11.6)$ & $14.1(6.2)$ \\
\hline May & $18.8(9.5)$ & $13.5(8.6)$ \\
\hline June & $20.5(9.5)$ & $14.7(8.3)$ \\
\hline July & $21.8(10.0)$ & $15.4(8.7)$ \\
\hline August & $17.7(17.7)$ & $14.2(14.2)$ \\
\hline September & $19.2(9.1)$ & $31.1(14.3)$ \\
\hline October & $26.3(14.3)$ & $98.8(52.0)$ \\
\hline November & $25.8(10.9)$ & $62.3(30.7)$ \\
\hline December & $27.3(14.3)$ & $166.3(24.9)$ \\
\hline
\end{tabular}

Lower standard error values (and associated standard deviations) are highlighted in bold (in this case errors less than or equal to $17 \mathrm{~W} \mathrm{~m}^{-2}$ ). 
(a) January Average Standard Error

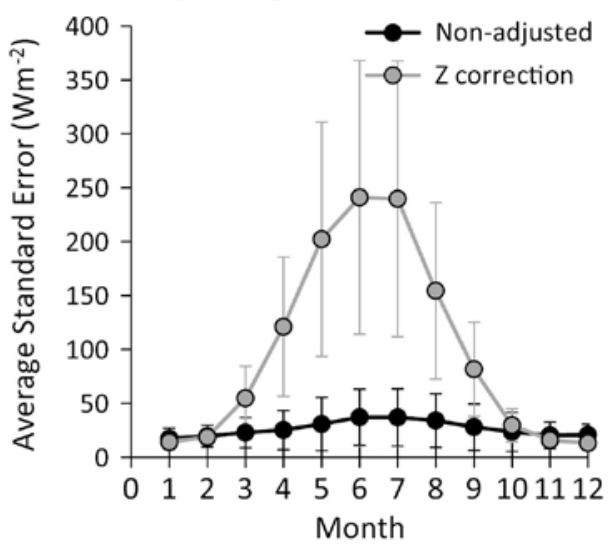

(b) May Average Standard Error
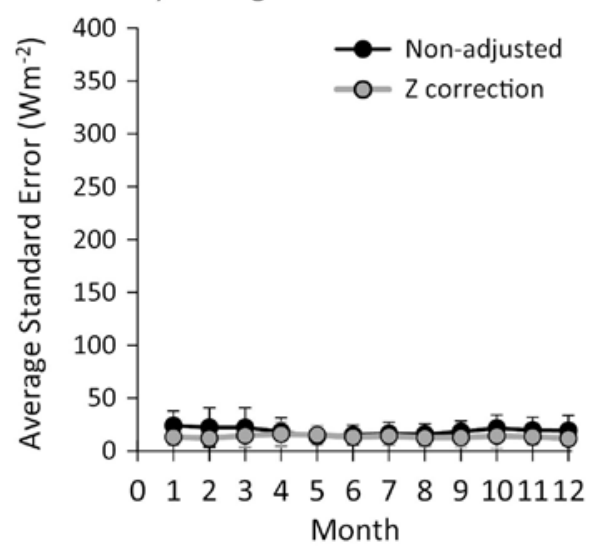

Fig. 7. Average validation results for all sensors, all calibration pairs over the 5-year study in a) January and b) May.

and sometimes clearly result in erroneous values (Table 3; see Fig. 7 as an example for calibrations in January and May). Results for May indicate that there is a slight advantage in using the adjusted calibration approach ( $Z$ only) rather than the non-adjusted linear calibration approach, while results for January indicate large errors in estimates can result when the Januaryadjusted calibration is used to estimate global irradiance for the summer months. The results are attributed to the limited range of $Z$ during winter months. In addition, under cloudy sky conditions, the radiation is largely diffuse, so the solar zenith angle is not controlling the direction of the radiation and the quality of the light differs from that during calibration. Using the adjustment for $Z$, the accuracy of the calibration under cloudy conditions was likely decreased. This likely further contributed to the poor performance of the calibration during the winter months. In the future, a calibration should be considered, where the fractions of direct and diffuse radiation are known and utilized in the calibration and application to improve global irradiance estimates.

When pyranometer age was considered, the "new" pyranometers performed better than "old" sensors and no clear advantage of one calibration approach over the other was found (Table 4). For the new sensors, the nonadjusted linear calibration provided estimates with a lower error (Table 4, text in bold for SE $<17 \mathrm{~W} \mathrm{~m}^{-2}$ ) for all months. For example, calibrations conducted during February through September performed better than those conducted in the remaining months. Non-adjusted linear calibration of older pyranometers yielded SE values generally $10 \mathrm{~W} \mathrm{~m}^{-2}$ greater than those for new sensors for the same month. Adjusting the new pyranometer calibrations for $Z$ diminished the calibration performance for February through September (an increase of SE of 2 or more $\mathrm{W} \mathrm{m}^{-2}$ ), while adjusting the old pyranometer calibrations for $Z$ improved calibration performance 
Table 4. Comparison of average standard error (SE) of validation(and the standard deviation for the average standard error in parenthesis) over the 5-year study period for the two calibration approaches for newer and older Li-Cor pyranometers.

\begin{tabular}{|c|c|c|c|c|c|}
\hline \multirow{3}{*}{$\begin{array}{l}\text { Calibration } \\
\text { month }\end{array}$} & \multirow{3}{*}{$\begin{array}{c}\text { Average } \\
\text { number of } \\
\text { clear sky days } \\
\text { per year }\end{array}$} & \multicolumn{4}{|c|}{ Overall SE for calibration approach } \\
\hline & & \multicolumn{2}{|c|}{ Non-adjusted } & \multicolumn{2}{|c|}{ Adjusted $Z$ regression } \\
\hline & & Old $\left(\mathrm{W} \mathrm{m}^{-2}\right)$ & New $\left(\mathrm{W} \mathrm{m}^{-2}\right)$ & Old $\left(\mathrm{W} \mathrm{m}^{-2}\right)$ & New $\left(\mathrm{W} \mathrm{m}^{-2}\right)$ \\
\hline 1 & 4.8 & $32.5(10.7)$ & $20.0(3.2)$ & $109.6(102.0)$ & $88.1(78.2)$ \\
\hline 2 & 2.4 & $24.6(6.4)$ & $15.6(2.9)$ & $304.2(276.8)$ & $181.1(155.3)$ \\
\hline 3 & 5.6 & $27.0(7.7)$ & $13.0(1.6)$ & $15.3(8.4)$ & $19.5(8.5)$ \\
\hline 4 & 0.8 & $26.5(7.4)$ & $13.0(2.0)$ & $11.1(5.0)$ & $17.2(6.8)$ \\
\hline 5 & 2.0 & $24.8(4.4)$ & $12.9(2.1)$ & $10.2(1.1)$ & $16.7(2.0)$ \\
\hline 6 & 2.4 & $26.0(6.4)$ & $15.0(2.3)$ & $12.0(2.5)$ & $17.4(4.1)$ \\
\hline 7 & 2.6 & $27.4(5.9)$ & $16.2(2.7)$ & $12.4(1.6)$ & $18.3(2.9)$ \\
\hline 8 & 4.4 & $22.4(5.7)$ & $12.9(2.1)$ & $11.3(2.6)$ & $17.0(3.0)$ \\
\hline 9 & 6.0 & $23.9(4.6)$ & $14.6(3.2)$ & $29.8(24.6)$ & $32.5(24.1)$ \\
\hline 10 & 7.6 & 32.5 (10.7) & $20.0(3.2)$ & $109.6(102.0)$ & $88.1(78.2)$ \\
\hline 11 & 5.0 & 31.1 (10.5) & 20.5 (5.6) & 62.7 (56.9) & $61.9(54.1)$ \\
\hline 12 & 4.8 & $33.3(12.2)$ & $21.3(5.1)$ & 169.5 (161.8) & $163.1(153.7)$ \\
\hline
\end{tabular}

Adjustments were derived in a 1-month window. Lower standard error values are highlighted in bold (which are average standard errors less than or equal to $17 \mathrm{~W} \mathrm{~m}^{-2}$ ).

(SE decreased by $\geq 5 \mathrm{~W} \mathrm{~m}^{-2}$ ), making global irradiance estimates comparable to, and at times better than, the global irradiance estimates for the new sensors using the non-adjusted linear calibration approach.

The effect of pyranometer age on global irradiance estimates is further demonstrated with plots of raw $\mathrm{mV}$ sensor output over the 5-year period for times when the PSP was measuring global irradiances between 499 and $501 \mathrm{~W} \mathrm{~m}^{-2}$ (Fig. 8). The "new" sensors (Fig. 8b) have smaller variations

(a)

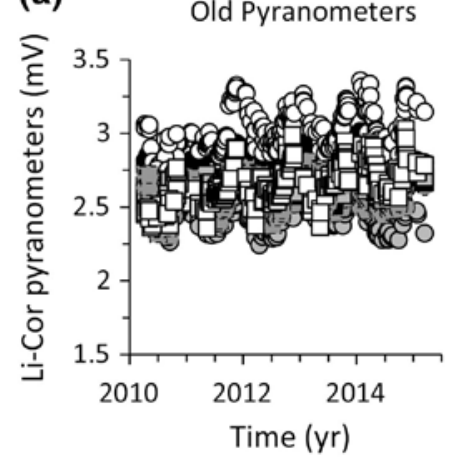

(b) New Pyranometers

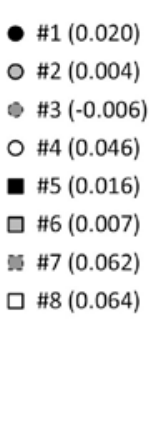

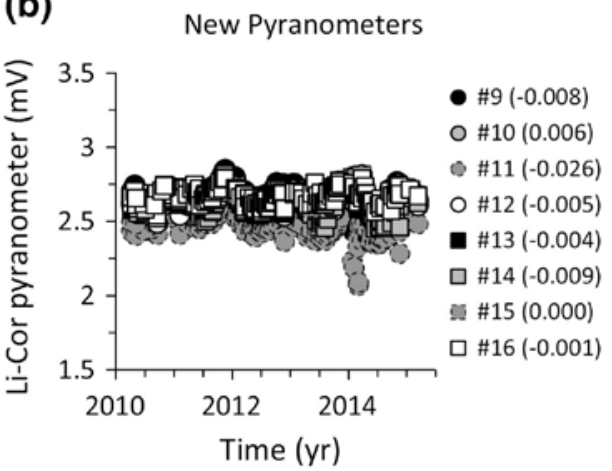

Fig. 8. Drift in LI-COR LI-200 pyranometer mV response for Eppley PSP solar irradiance of 499-501 W m-2 over the years (all sky conditions): a) old sensors; and b) new sensors. Values in parentheses indicate the slope of the trendline of the $\mathrm{mV}$ response over the 5 -year period for each pyranometer. 
throughout the experiment period than the "old" sensors (Fig. 8a). The greater variation in the old sensor raw $\mathrm{mV}$ output is consistent with the finding that calibrations including adjustment for $Z$ improve global irradiance estimates for the older sensors. Age effect could be due to change in the internal sensor or in the diffusing material. Changes due to aging and weathering have been noted for photovoltaic modules (Kaplanis and Kaplani 2011). Further study is warranted.

\section{Conclusions}

The effects of calibration approach, calibration timing, and sensor age on errors in estimating global irradiance were investigated. Calibrations which accounted for solar zenith angle and temperature effects improved global irradiance estimates for older SiPs (in service for seven or more years), but obtaining a wide range of temperatures and solar zenith angles requires a year of calibration data. Monthly calibrations are recommended using the adjusted calibration approach (adjusting for solar zenith angle only), with reliable results for calibration months of April through August, as evidenced by smaller standard errors in these months when using a range of sensor ages. However, the age of the sensor should be considered as older sensors apparently become more sensitive to solar zenith angle (and air temperature), such that the response drifts more over time than it does with the newer sensors.

Validation results for each solar zenith angle monthly calibration indicates certain calibration months provide a defendable validation across the following 12 months (with average standard errors ranging from 13.5 to $17.4 \mathrm{~W} \mathrm{~m}^{-2}$ ), while other calibration months do not provide consistent results and sometimes may result in very poor validation $\left(31.1-242.7 \mathrm{~W} \mathrm{~m}^{-2}\right.$ average SE). At the mid-latitude location for this study, a slight advantage is indicated for using the adjusted solar zenith angle calibration approach rather than the non-adjusted linear approach for calibration in the month of May across all months of the year (13.5 and $18.8 \mathrm{~W} \mathrm{~m}^{-2} \mathrm{SE}$, respectively), while large errors in estimates are indicated using both approaches for calibration in the month of January for the summer months (98.8 and $26.3 \mathrm{~W}$ $\mathrm{m}^{-2}$ average SE, respectively).

When SiP age was considered, the newer (less than 6 years) SiPs performed better than older sensors (greater than 6 years) and no clear advantage was found for one calibration approach over the other. Calibration of older SiPs for the non-adjusted linear calibration was poorer than for the newer SiPs, with SE values generally $10 \mathrm{~W} \mathrm{~m}^{-2}$ larger than with the new sensors for the same month. Adjusting the new SiP calibrations for solar zenith angle diminished calibration performance (an increase in SE of around $2 \mathrm{~W}$ 
$\left.\mathrm{m}^{-2}\right)$. Adjusting the old SiP calibrations for solar zenith angle improved calibration performance (SE decreased by $5 \mathrm{~W} \mathrm{~m}^{-2}$ or more), making the global irradiance estimates comparable to, and at times better than, global irradiance estimates for the new sensors using the non-adjusted linear approach.

Further study is warranted into the effect of sensor age on calibration results. The "new" sensors varied less over the study period of constant global irradiance values than the "old" sensors. Thus, the standard errors in the validation were larger for the "old" sensors than for the "new" sensors, with an improvement in calibration when adjusting for solar zenith angle. The age effect could be due to a change in the internal sensor or in the diffusing material. In addition, calibrations accounting for the diffuse component need to be explored. Diffuse irradiance differs from direct irradiance in the direction of the sun, such that SiPs measuring diffuse irradiance respond differently under cloudless sky than under skies covered with clouds (Vignola et al. 2016). The calibrations in this study were conducted using data for clear sky conditions, while the validation was performed using data representing all sky conditions. The light quality differs from that during calibration and solar zenith angle correction would not be needed under cloudy conditions. Various corrections have been applied to SiPs to compensate for effects of temperature, spectral sensitivity, and cosine error in rotating shadow band applications (Geuder et al. 2014; Vignola et al. 2016; Al-Rasheedi et al. 2018). Perhaps, these approaches could be adapted in the future to serve in a "smart" calibration, where the fractions of direct and diffuse radiation are known and utilized in the calibration and application.

For the Lincoln NE location, the appropriate calibration is in spring or late summer, regardless of calibration approach. Software developed in this project can be used to calibrate SiPs for other locations, where data are available and can determine the time of year most suitable for valid calibration.

Acknowledgments - The authors thank Drs. Martha Shulski and Timothy Arkebauer for their review of the manuscript and their constructive comments and suggestions. This work is supported by the USDA National Institute of Food and Agriculture Hatch project no. 1002649.

\section{References}

Aceves-Navarro LA, Hubbard KG, Schmidt J (1988) Group calibration of silicon cell pyranometers for use in an automated network. J Atmos Ocean Tech 5(6):875879. doi.org/10.1175/1520-0426(1988)005\%3C087 5:GCOSC P\%3E2.0.CO;2

Al-Rasheedi M, Gueymard CA, Ismail A, Hussain T (2018) Comparison of two sensor technologies for solar irradiance measurement in a desert environment. Solar Energy 161:194-206. doi 10.1016/j.solen er.2017.12.058 
ASTM Standard E 824. 2010 (2010) Standard test method for transfer to calibration from reference to field radiometers. ASTM International, West Conshohocken. doi.org/10.1520/E0824 -10

Geuder N, Affolter R, Kraas B, Wilbert S (2014) Long-term behavior, accuracy and drift of LI-200 pyranometers as radiation sensors in Rotating Shadowband Irradiometers (RSI). Energy Proc 49:2330-2339

Kaplanis S, Kaplani E (2011) Energy performance and degradation over 20 years performance of BP c-SI PV modules. Simul Model Pract Theory 19:1201-1211. doi.org/10.1016/j.simpat.2010.07.009

King DL, Myers DR (1997) Silicon-photodiode pyranometers: operational characteristics, historical experiences, and new calibration procedures. In: IEEE photovoltaic spec conf 26th, Anaheim, CA USA, 1285-1288. doi.org/10.1109/ pvsc. 1997.654323

King DL, Boyson WE, Hansen BR, Bower WI (1998) Improved accuracy for lowcost solar irradiance sensors. In: 2nd world conf. exhib. photovoltaic sol. energy conv., Vienna, Austria. http://energy.sandia.gov/wp-conte nt/gallery/uploads/ LowCostSensors King-Boyson-etal.pdf Accessed 29 Jun 2017

Myers DR (2011) Quantitative analysis of spectral impacts on silicon photodiode radiometers. In: SOLAR 2011 Conf, Raleigh, NC, May 17-21. http://www.nrel. gov/docs/fy110 sti/50936.pdf Accessed 24 Feb 2018

Vignola F, Derocher Z, Peterson J, Vuilleumier L, Félix C, Gröbner J, Kouremeti N (2016) Effects of changing spectral radiation distribution on the performance of photodiode pyranometers. Sol Energy 129:224-235 